\title{
Integrating IS success model with cybersecurity factors for e-government implementation in the Kingdom of Saudi Arabia
}

\author{
Mohammed Saeed Al-Zahrani \\ Department of Computer Networks and Communications, \\ College of Computer Science and Information Technology, King Faisal University, Saudi Arabia
}

\begin{tabular}{l} 
Article Info \\
\hline Article history: \\
Received Jan 29, 2020 \\
Revised Feb 29, 2020 \\
Accepted Mar 22, 2020 \\
\hline
\end{tabular}

\section{Keywords:}

Cybersecurity factors

E-gov effectiveness

IS success model

Privacy

Service quality

TAM

Wide area network

\begin{abstract}
The electronic government (E-Gov) systems are currently getting recognized as an authentic strategically tool in delivering E-services. Considering the development of information system (IS) as well as the expanding of the internet-based applications in KSA, E-Gov has always been a significant aspect in delivering governmental services. This research has adopted the (IS) success model by both DeLone and McLean (D\&M), moreover, it adopted technology acceptance model (TAM) with cybersecurity factors, both models were implemented to discover the status of the IS success then investigate cybersecurity aspects that impact the service efficiency and effectiveness in KSA. Consequently, this research aims to create a model to investigate the IS success model along with cybersecurity factors that influence E-Gov services effectiveness and usage. Therefore, a survey has been applied as the major data gathering approach; the survey has been distributed among 211 users of E-Gov services consistently. Moreover, all research findings were attained through a quantitative method using the structural equation modelling (SEM). Findings revealed that the constructs fundamental of the (IS) success model are strongly influencing users' satisfaction (US) of the E-Gov services; correspondingly, the fundamental constructs factors of cybersecurity with TAM appear to have a strong impacts on perceived risk (PR), in addition, both which affect the E-Gov services towards usage and effectiveness.
\end{abstract}

Copyright $(2) 2020$ Institute of Advanced Engineering and Science. All rights reserved.

\section{Corresponding Author:}

Mohammed Saeed Al-Zahrani,

Department of Computer Networks and Communications,

College of Computer Science and Information Technology,

King Faisal University,

P.O.Box: 400 Alhasa 31982, Saudi Arabia.

Email: malzahrani@kfu.edu.sa

\section{INTRODUCTION}

The core idea of Electronic government (E-Gov) based on using information technology (IT), as well as the (IS). For instance; the internet usage, wide area network (WAN), in addition to mobile computing to extend all operations that are controlled by government as well as providing both organizations and individuals with more appropriate accessibility to the needed services and information [1]. The problem of this research is addressing the considers to be a new governmental technology to facilitate, support then automate operations among itself and both businesses and constituents, or other governments [2]; it is unfortunate that, in developing countries the diffusion process continues to remain slow including KSA. Moreover, this IT diffusion gap among both developing and developed countries could be caused by the differences on socio-economic which prevent the accessibility to IT. Consecutively, variations in 
education rates or the incapability use of IT might be the main reason for this gap to occur. E-Gov is an essential factor of any government modernization, aiming to enhance the accountability, transparency, and decent governance; helping the government to be further result-oriented, more effective and citizen-centred in KSA; besides allowing both businesses and citizens to easily access information besides governmental services as efficiently and effectively as possible through the internet and any additional suitable communication channels [3].

E-Govs are getting more momentum in numerous countries due to its suitability and efficiency beyond several public services contexts. It gives citizens the ability of having greater information access, improving service delivery, transparency promoting, along with increasing public government affairs participation [4, 5]. IT usage various governmental sector extends great prospects for improving service quality (SeQ) and proficiency besides reducing the governmental operating expense. Operational combined with Efficient E-Gov simplifies greater and further effective way in information delivery besides providing services among citizens, promoting productivity beyond public servants, inspires government participation among citizens, as well as empowering all citizens [6]. Nevertheless, the diffused malfunction of E-Gov application indicates that E-Gov frequently creates unsophisticated enthusiasm [7]. Moreover, among developed countries for instance Canada, the U.S., along with Finland is yet leading the E-Gov field among the world. The age of information promises of a powerful and innovative weapon among the developing countries arsenals. Developing countries are struggling against political, economic, and social challenges. Accordingly, E-Gov platforms deliver a possibility for additional governance to both business and citizen contribution in the government, which might create less social influence than what is happening in Western countries. Consequently, additionally, it is crucial to investigate both implications along with the impact of E-Gov around developing countries [8].

In Spite of E-Gov initiatives potential, its adoption and implementation still have a quantity of challenges. For instance, previous literature reported that practices through E-Gov initiatives as 'unmanageable' or 'chaotic' [9]. Even with several initiatives at various stages of both government practitioners' and academic conferences on E-Gov across the globe [10]. Also, many cases of inadequate websites design and several challenges that appeared to emerge among E-Gov services consumers. Consequently, the efficient utilization of evaluative methods towards determining the websites quality could improve the efficacy of these websites, thus persuade users to utilize them [11]. Thus, the determined reasons for this are privacy issues, trust issues, security concerns, and risk factors [12]. Nevertheless, many additional factors mentioned by [13] like; influencing E-Gov usage (EU) by citizens. Though E-Gov is getting widespread in addition to have a high influence upon people's lives alongside organizations performance, yet it is far as of accomplishing its purpose as a universal electrical marketplace besides accomplishing efficiency within the process, more specifically among Arabian nations [14]. Referring to E-Gov development status, it is considered to be crucial to yet achieve a comprehensive method set that simplifies the most suitable improvements identification in performance after the technological innovation's implementation such as E-Gov applications. The (IS) success measurement or efficiency was and still broadly examined through the community of IS research [15]; nevertheless, theorists yet are facing some issues of which concepts best determine IS success [16]. Consequently, the main aim of this research is developing a model to investigate the model of (IS) success along with cybersecurity factors, which affect E-Gov public service effectiveness along with its usage in KSA.

Kingdom Of Saudi Arabia (KSA) E-Gov. This research targeted the (KSA) as it is a greatly prominent developing economy among the Middle East combined with North Africa (MENA) area, which has been investing greatly within the E-Gov field. Likewise, comparing to other developing economies, KSA holds a specific concentration upon delivering government service sector by electronic means [11]. However, there was no significant progress has been accomplished related to E-Gov developments. Furthermore, in 2016 the United Nations reported that KSA was rated in the 44th among the list comparing to the 36th that was held on 2014 along with 41st in that was held on 2012 [17]. Whilst earlier research regarding E-Gov use in the KSA is mainly focuses on issues like E-Gov technologies acceptance among citizen [18, 19].

Moreover, adopting more usable methods regarding digital transformation besides the IT environment in general [20], development in security transaction along with IT necessity for training among governmental workers [21], assessments of governmental websites among the state [11], as well as studying the factors that have hindered the application and accomplishment of the government's plans along with vision [22]. While KSA government is spending considerable funds to initiate in the application of E-Gov in order to re-structure their procedures, however, the point where these inventions actually support the businesses industry to enhance the efficiency of their procedures yet requires further investigation [23]. Operational efficiency is linked with the capability to determine the actual processes, which based on the main abilities among these businesses that allow them to meet or even go beyond clients' anticipations [24]. Present literature seems to investigate in what way E-Gov initiatives could enhance the service characteristics 
of E-Gov like; service quality (SeQ), information quality (IQ), and system quality (SQ) [25]. However, some researches, based in our knowledge, have associated these approaches characteristics with (IS) success model e.g., SeQ, IQ, SQ, with US; additionally, cybersecurity factors with TAM model e.g., perceived risk (PR), perceived privacy (PP), and perceived security (PS) of E-Gov services in KSA.

\section{RESEARCH MODEL AND HYPOTHESES DEVELOPMENT}

\subsection{Theoretical background}

The IS success model is an additional valuable theoretical basis to explore the continuation use of IS [26]. Furthermore, Hsu, Chiu, and Ju [27] examined the significance of IS success model three quality concepts in order to recognize the continuous intent behaviour of the IS: SeQ, IQ, and SQ. Additionally, those concepts allow the quality E-Gov service to be evaluated. DeLone and McLean [28], DeLone and McLean [26] identified the quality as an evidence of its quality in a system's whole performance and thus, it could be evaluated by individuals' experiences. Since consumers are anonymous in the interactions of E-Gov, the IQ of these systems happens to be the "online storefront" whereas the first impressions are founded. Moreover, if individuals recognize that E-Gov system has a high quality; this could encourage these individuals to make use of internet systems for applications submission or accessing all E-Gov services electronically [29]. Furthermore, the model of Technology acceptance was established by Davis et al. [30] thus, originally it included perceived ease of use (PEU), perceived enjoyment and perceived usefulness (PU) as factors that influence technology acceptance. TAM models are regularly modified then utilized for E-Gov acceptance investigation $[31,32]$.

\subsection{Hypotheses development}

This study has been formulated based on some models: the National Initiative for Cybersecurity Education cybersecurity capability maturity models (NICE-CMM) and National Institute of Standards and Technology (NIST) Cybersecurity Framework [33]; US Department of Homeland Security 2014), the extended unified theory of acceptance and use of technology (UTAUT2) [34] and the affective decision-making theory of optimism bias and risk [35]. As demonstrated in Figure 1, fifteen hypotheses were developed among twelve concepts mostly has been selected among models of IS success [26, 36] then several added concepts (such as PU, PEU, attitude towards use, and perceived trust (PT)) to investigate the significance and strengths of relationships on E-Gov service usage, besides consumers satisfaction picked up from TAM [30]. The formulation of every hypothesis is explained in the sub-sections followed see Figure 1.

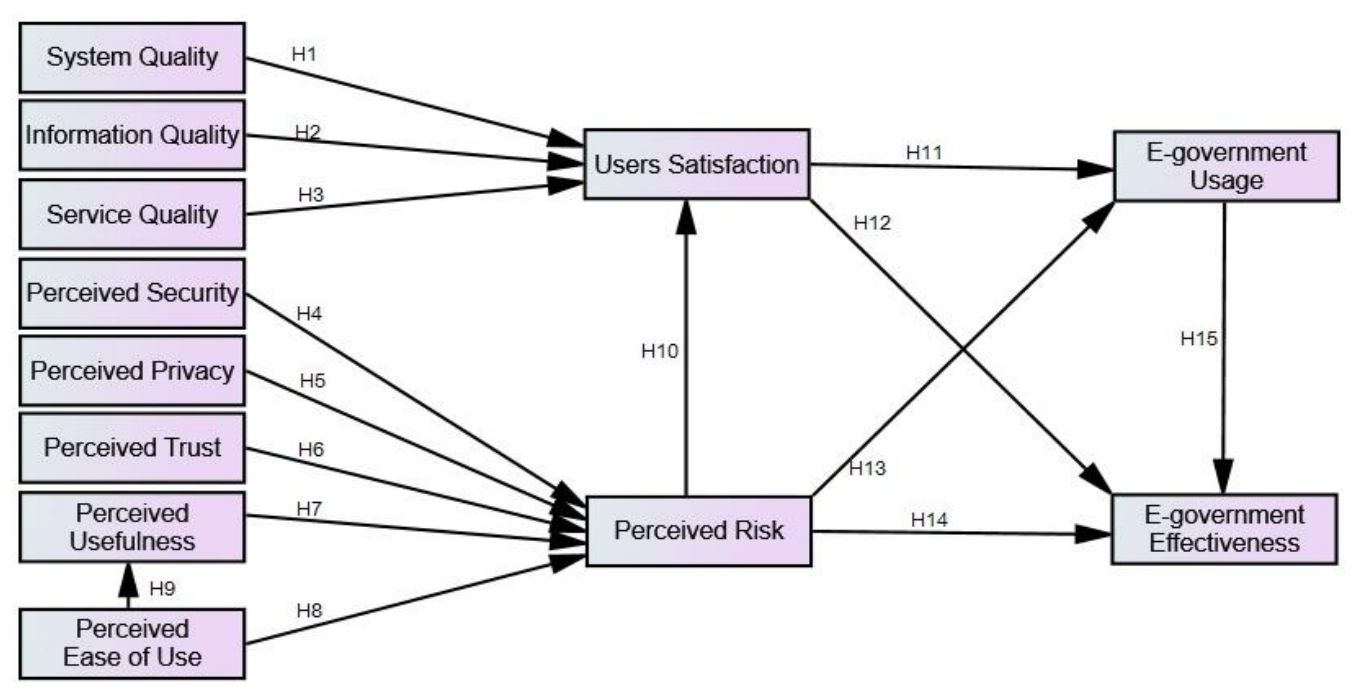

Figure 1. Research model and hypotheses

\subsubsection{System quality (SQ)}

SQ signifies online approaches qualities that is selected based on its reliability, adaptability, usability, availability, and the time of response [26]. Additionally, it signifies the website technical abilities in delivering easy along with quick access to data to the customer whereas confirming the security and 
reliability [37]. Researches have also proven such a correlation in the E-Gov [37, 38]. IQ defines a government website's capability to deliver well-timed, precise, comprehensive, brief, and appropriate information in line with citizens' demands [39]. Based on the E-Gov service development stages that has been discussed in diverse research [9], even though E-Gov services has been developed progressively from its original static phase which was characterized by autonomous information to be an interactive phase. Whereas they could handle formal business among the government and its public, yet, IQ is a vital factor of high-quality online public service and a decent client practice [40].

\subsubsection{Information quality (IQ)}

IQ describes consumer's assessment of IS performing within delivering information based on its capability of system use [41]. Furthermore, this type of evaluation is about the IS websites that are expected to have being customized, completed, easy-to-use and appropriate, as well as providing all aspects of security to support transactions online [26]. Additionally, (SQ) is developed throughout the interaction along with the system, whereas users end a particular task [42]. SQ describes a user-friendly arrangement of governmental websites, such as website design, navigability, usability, and operation modules [43, 44].

\subsubsection{Service quality (SeQ)}

$\mathrm{SeQ}$ describes the level of service obtained by E-Gov application users, and the method where the service will be offered by the IS/IT department whereas it affects level of satisfaction along with the application of E-Gov [26, 45]. Based on Moad [46], the IS/IT department's SeQ are recognized among users as a major sign of EIS success. The IS/IT department's capability to provide installation support, software training, product information, online help, and support is a factor that affect the correlation amongst users and IS/IT [45]. Consequently, the correlation among the end users and IS/IT unit must have efficacy among day to day operations in addition to the organization operational performance [47]. Additionally, to confirm the transparency and accountability, the completion service process must be manageable, then citizens must be notified of service status through formal e-mails along with texts that are mailed to them from governmental staff websites [44].

\subsubsection{Perceived security (PS)}

As the utilization of smart technologies rises, E-Gov organizations cope with providing security challenges. The subsequent generation of E-Gov systems should incorporate with other types of services like; public deliberation data, regulatory publications, and geospatial information, which improves the applications innovation along with the experience itself [48]. Moreover, possible Threats towards E-Gov is this case could be more complicated, aiming the back-end servers, customer end points, and the communications infrastructure [49]. Therefore, government systems implementation to deliver efficient and effective services throughout the Internet, still the matter of security and privacy threats continue to be the most important concern. Privacy violations and identity theft are still major threats [50]. Consequently, TAM has been effectively utilized in modelling the electronic government services acceptance. Gilbert et al. [51] used TAM to detect security, trust, information time and quality as considerable factors that could be influencing E-Gov services usage which by employing attitudinal technology model adoption. Shareef et al. [31] modified E-Gov acceptance model considering variations in E-Gov acceptance on a number of maturity levels. Thus, their findings additionally revealed that the exchange that happens among the security solution difficulty and user-friendliness in E-Gov systems. Rehman et al. [32] utilized his model based on TAM to detect IQ as a critical aspect in E-Gov system, in addition to more factors of transaction security, SeQ, and PEU. Bélanger and Carter, [50] examined the nature of trust together with results that positively affects consumers' trust in government and beyond their targets to E-Gov services acceptance. Horst et al. [52] discovered trust to be the key factor affecting the E-Gov services perceived effectiveness.

\subsubsection{Perceived privacy (PP)}

E-Gov users have concerns about privacy violation and insecurity, and this might be a significant burden of E-Gov deployment and its further successful management. Eynon [53] claimed that such concerns can be a main reason to accept E-Gov services by users, moreover, failures in this extent could cause distrust among administrative capability of all authorities involved to be able to operate public services. Privacy matters are recognized as a crucial legislation challenge, policy, and instructions, in the 21st century [54]. E-Gov systems accumulate many classified information about different individuals, besides many types of financial transactions. If this type of information is compromised, then this might be a major reason to loss trust in E-Gov and its services [55]. Alshehri and Drew [21] claim that security and privacy should be secured to expand trust by the users, whilst interacting with E-Gov services. One main concern regarding government systems is securing besides using of sensitive and personal information, in addition, there are 
concerns that these types of information might be used to observe the consumers, which is considered as an invasion by many consumers to their personal privacy [56]. It is a governmental duty to guarantee that all consumer's information is protected, then their privacy is well-preserved throughout collecting their data, processing the data, storage, besides exchange it. Consequently, the E-Gov infrastructure besides any devices that are linked to the infrastructures must be shielded through proper measures. Security, and privacy are crucial elements to gain E-Gov systems users trust, as well as it is an essential significance to shield individual's privacy to be able to develop trust in E-Gov development and initiatives [57]. Moen et al. [58] argued that there are many E-Gov websites that doesn't have privacy policy within.

\subsubsection{Perceived trust (PT)}

The trust concept could refer to various meanings, and it is considered to be a major concern in a diversity of human endeavour scopes [16]. Nonetheless, this has caused a great flow of studies on the concept of trust; additionally, it caused a variety of conceptualizations forms [16]. Furthermore, in research trust frequently quoted as one of the furthermost conceptions examined in marketing research relationship [59]. Furthermore, trust among government, business and citizens is important for decent governance as well as participation [60]. Trust, moreover, has been identified as a major enabler for effective application along with technical innovations adoption like E-Gov systems and structures [61]. Nevertheless, Dombrowski, Hayes, Mazmanian, and Voida [62] indicated all types of challenges that is related in a way or another to trust and its cultivate and support, which is more important than all required technical skills in order to interact with the E-Gov system. Many researchers have examined E-Gov role and trust [61]. While trust has been modelled as E-Gov service use outcome in many conditions [63], Moreover, this suggested model, we agree along with many researchers, like; [52, 64] whereas they have depends in trust as a major factor regarding E-Gov service satisfaction or adoption. Moreover, E-Gov services trust has been noticed to have a considerable participation antecedent in business in general, particularly in virtual and online environments due to the simplicity that online shops offer [65]. Additionally, Papadomichelaki and Mentzas, [39] and Welch et al. [66] have claimed a positive relationship among E-Gov service characteristics and trust. According to these outcomes we assume that trust has a positive impact on E-Gov systems evaluations as determined by SeQ, IQ, and SQ.

\subsubsection{Perceived usefulness (PU)}

TAM categorizes the baseline technology factors of PU acceptance, along with PEU along with awareness of any technology around. The model of technology acceptance has been further established [30, 67], moreover, this model offers precise anticipations regarding accepting technology [68]. The model of technology acceptance has been employed in modelling several of E-Gov services acceptances. For instance, [51] utilized TAM to detect both trust, and IQ as major aspects that influence the E-Gov services usage through utilizing attitudinal technology adoption model. Additionally, the correlation amongst the PU along with attitude towards utlizing E-Gov adoption has been examined in few researches [69, 70].

\subsubsection{Perceived ease of use (PEU)}

Hung et al. [69] observed that PEU considerably affects E-Gov service attitudes. Respectively, Hung et al. [69] noted that PEU have being a considerable interpreter of utilizing electronic system. Additionally, Hung et al. [70] studied both mobile E-Gov services and government to-business in Taiwan, thus, claimed that the correlation among PEU along with attitude regarding utilizing the corresponding E-Gov service stayed significant for both aspects. Furthermore, there are several studies in E-Gov research $[29,40]$ that have additionally implemented TAM into their developed model to evaluate or exam citizen acceptance of E-Gov services. Both PEU and PU were observed to have considerable constructs in the adoption of E-Gov [40, 71].

\subsubsection{Perceived risk (PR)}

Risk could be described as "a situation or event where something of human value (including humans themselves) has been put at stake and where the outcome is uncertain" [72]. PR is correlated towards the undefined behaviour outcome [73], Furthermore, Evidence of the association among PT along with risk in E-Gov are appeared to be very complicated. Belanger and Carter [50] noticed that government trust, but not Internet trust, to show a considerable negative impact on E-Gov services PR, additionally, that PR had a negative effect on E-Gov usage. Horst, Kuttschreuter, and Gutteling [52] mentioned that e-services PR affected trust negatively in E-Gov. Consequently, the major key to have an effective risk communication depends on government's capability to notify citizens regarding risks emerging in a timely manner and assist them create their own choices [74]. Furthermore, Almarashdeh and Alsmadi [75] argued that once citizens face high risk in E-Gov system usage, there will be a widespread possibility of delaying the online 
transaction then looking for an alternative channel. Taking into consideration the suspicion regarding online-based transactions besides the considerable possibility of cyber-attacks, this research suggests that PR has a major influence on the decision made to the idea of using and accepting E-Gov systems. Numerous researches such as $[76,77]$ mentioned that there is a negative effect of risk perception on the decision made on using E-Gov systems.

\subsubsection{Users satisfaction (US)}

DeLone and McLean's [28] claimed that IS success model suggests that IQ also impacts consumer satisfaction. Consumer Satisfaction describes the subjective evaluation of multiple experiences faced by an IS consumer [36]. Findings of many researches that adopted the (IS) domain have tried to clarify the relationship among consumer satisfaction, behavioural intention and attitudes towards system usage [27, 67, 78]. Several researches on IS success have supported the argument that; higher IQ leads toward enhancing the satisfaction of E-Gov consumers [15, 79, 80]. Additionally, Rana et al. [81] showed that IQ and SQ considerably influenced behavioural intentions and consumer satisfaction. Furthermore, the IQ meta-analysis of consumer satisfaction additionally showed a considerable correlation among them in E-Gov exploration context [82]. Chen [83] examined the satisfaction of taxpayer's along with online system intended for categorizing individual's income tax returns in Taiwan context. Gotoh [84] proposed an analysis for Japanese government of the online tax declaration services, moreover, empirically analysed it to expose the aspects that improve consumer satisfaction along with these services. Furthermore, claimed a significant relations of consumer satisfaction in several researches related to the adoption of E-Gov [85, 86]. Furthermore, Floropoulos et al. [80] discovered that there is a significant influence between service qualities on consumer satisfaction. Furthermore, Wang and Liao [15] showed that there was a low relation between service qualities on consumer satisfaction whereas assessing the E-Gov systems success.

\subsubsection{E-Gov ssage (EU)}

EU is the strength measure of individual's intent towards operating specific actions. Based on the intention-based theories, consumer usage behaviour and adoption are established by the intent of using IS/IT. Additionally, Bélanger and Carter [50] investigated the disposition of trust with results that influences consumer trust positively in government then furthers their intentions of accepting E-Gov services. Based on the theoretical foundations, the IS continuance model has been utilized to clarify post-adoption behaviour intention in several IS situations, including E-Gov [87, 88]. Whereas the E-Gov services domain, the results of prior studies revealed a positive relationship among PEU, EU and PU [89].

\subsubsection{E-Gov effectiveness (EE)}

Improving and maintaining the performance has considered being a major matter that corporations are competing through [90]. Additionally, it is predictable that innovations in technology like E-Gov systems are able to cause considerable profits among governments and businesses which contain reducing communication along with information expenses, speed maximization, eradicating distance, as well as broadening reach [10]. Furthermore, E-Gov systems services allow organizations to successfully operate information internally as well as providing effective services [91]. Consequently, E-Gov systems potentially aid organizations in enhancing their performance and efficiency. Effectiveness of E-Gov systems must be evaluated based on the real operational profits instead of the (IS) outcomes achievement only. Consequently, it is essential to relate effectiveness privacy, risk, measures on security, and trust with E-Gov efficiency dimensions SeQ, IQ, SQ, PU, PEU, and the E-Gov use attitude and consumer satisfaction. The previous literature recommends the absence of focus in several incidents, however, the operational effectiveness concept that might clarify the gap among the E-Gov services supply and their adoption has been neglected in these literatures. Even Though it is acknowledged that E-Gov systems could benefits both governments and businesses [10, 91], Yet, there are few negative aspects that has been mentioned in regard to E-Gov initiatives [9]; additionally, Savoldelli et al. [92] described it as the 'E-Gov paradox', where after two decades of elevated expenditures still there is no results to justify these claims.

\section{RESEARCH METHODOLOGY}

This research was built based on the updated IS success model and TAM model with respect to development of a conceptual model of user's satisfaction of EE in KSA, in which quantitative method research was used through empirical study. In this recent study, the identified factors (i.e., SeQ, IQ, SQ, PS, PP, PT, PR, EE, US, EU, PEU, and PU), were used to form a structured survey with five-point scale and administered to a larger sample (56 items), the population selected through simple random sampling size technique [93]. Two (2) experts validated the questionnaire by checking the face and content validation. 
Collected data from King Faisal University (KFU), and have being evaluated with IBM SPSS, and structural equation modelling (SEM- Amos). IBM SPSS and SEM-Amos are believed to be the master statistical technique employed in this current study which involves dual stages; the first stage followed constructing the measures validity, discriminant validity of the measurement, convergent validity of the measures, whereas, the second stage examined the structural model. Additionally, that technique was recommended by [94].

\subsection{Measurement instruments and data collection}

A total of 234 surveys samples were distributed amongst learners of November 2019 semester, from those 211 questionnaires were categorized as practical. In particular, the questionnaire included 56 items designed to extract particular information from the respondents. Hence, in this research, the researchers collected data utilizing survey through two sections; firstly, demographic data, and secondly, factors' measurement related with the previous theory. The core objective of this current study was to solicit the perspectives of users on their satisfaction of E-Gov effectiveness in KSA. As for the number of items used for each variable in E-Gov, SeQ, IQ and SQ, were adopted four items for each variable from previous studies [26, 36, 45]. Additionally, four items were adapted from [39, 95] to measure PS. Likewise, four items were adapted from $[31,96]$; to measure PP. As well, four items were adapted from [73] to measure PR. Additionally, Four items were considered from the study of [97] to measure PT in E-Gov. Five items were adapted from [30, 31, 85] to test the influence of both PEU and PU in E-Gov. Moreover, Five items were adapted from [98] to measure used E-Gov, and then, five items were adapted from [27, 78] to measure users' satisfaction. Finally, eight items were adapted from $[9,90]$ to measure E-Gov effectiveness.

\subsection{Sample characteristics}

The questionnaires were 211 for analysis samples, the male respondents were $113(53.6 \%)$; the female respondents were $98(46.4 \%)$. The age of respondents $41(19.4 \%)$ were in the range of 18-25 years old, 159 (75.4\%) were in the range of 26-33 years old, and $11(5.2 \%)$ were more than34 years old. Based on level of education of respondents, $95(45.0 \%)$ were from undergraduate level, 105 (49.8\%) were from postgraduate level "Master ", and 11 (5.2\%) were postgraduate level "PhD". The demographic factors of E-Gov services used, the first question is access internet through; 39 (18.5\%) were using mobile for E-Gov services, 105 (49.8\%) were using laptop for E-Gov services, 38 (18.0\%) were using personal computer (PC) for E-Gov services, and $29(13.7 \%)$ were using tablet for E-Gov services. Finally, the frequently of access internet for E-Gov services; 72 (34.1\%) were using E-Gov services daily, $112(53.1 \%)$ were using E-Gov services twice in week, $20(9.5 \%)$ were using E-Gov services fortnightly, and 7 (3.3\%) were using E-Gov services monthly.

\section{DATA ANALYSIS AND RESULTS}

Research instrument's reliability was computed using SPSS statistical software version 21, using Cranach's Alpha method to ascertain the extent of the homogeneity of the items. The results obtained shows that the reliability coefficients for the factors as follows: IQ were 0.911, SQ were 0.837, SeQ were 0.892 , PS were 0.926 , PP were 0.891 , PR were 0.866 , PT were 0.908 , PU were 0.859 , PEU were 0.888 , EU were 0.912 , US were 0.882 , and EE were 0.961 . On the whole, the reliability coefficient of the survey is 0.956 which indicates that the items in the questionnaire were internally consistent in measuring what was intended to be measured for the study. This current study measured discriminant validity across three different criteria, which are: variable index value below 0.80 [94], followed by value of AVE considered equal to or more than 0.5; square of AVE is bigger than inter construct correlations (IC) linked with factors [99]. Additionally, items and crematory factor of the construct's examination gave a factor loading equal to 0.7 or more, and supposed to be acceptable, having Cronbach's Alpha and composite reliability value equal or greater than 0.70 [94].

\subsection{Measurement model analysis}

This current research utilized SEM-Amos as the statistical technique for analysing the results based on confirmatory factor analysis (CFA) in AMOS 23. Moreover, this model analysed over consistency and discriminant validity, uni-dimensionality, and convergent validity. Additionally, Hair et al. [94] proposed that model assessment should be assessed through the highest likelihood estimation process by means of goodness-of-fit strategies. For example chi-square, normed chi-square, normed fit index (NFI), relative fit index (RFI), Tucker-Lewis coefficient (TLI) comparative fit index (CFI), incremental fit index (IFI), the parsimonious goodness of fit index (PGFI), rootmean-square residual (RMR) and root mean square error of approximation (RMSEA) are measured based on the study of [94], Table 1 shows the goodness of model fit. Also, Figure 2 (IS success Model), and Figure 3 (Cybersecurity Model) shows the measurement of all items and factors. 
In this current study, to calculate the discriminant validity three different criteria were used. One of these criteria is the correlation index between variables which is expected to be not more than 0.80 [94]. The other two are the value of the average variance extracted (AVE) and the square root of AVE. The desired value of the former is equal to or greater than 0.5 for each construct, whereas the value should be more than the inter-construct correlations (ICs) linked with that factor [99]. As for the crematory factor analysis, the factor loading is preferred to be 0.5 or greater, whereas it should be $\geq 0.70$ for Cronbach's alpha and $\geq 0.70$ for the composite reliability [94], see Table 2 .

Table 1. The goodness of model fit and reliability

\begin{tabular}{llll}
\hline Type of Measure & Acceptable Level of Fit & IS Success Values & Cybersecurity Values \\
\hline RMR & Near to 0 (perfect fit) & .036 & .032 \\
NFI & Value should be $=$ or $>0.90$. & .955 \\
RFI & Value should be $=$ or $>0.90$. & .974 & .963 \\
IFI & Value should be $=$ or $>0.90$. & .966 & .971 \\
TLI & Value should be $=$ or $>0.90$. & .979 \\
CFI & Value should be $=$ or $>0.90$. & .970 & .964 \\
RMSEA & Value $<0.10$ means a good fit and $<0.05$ & & .043 \\
\hline indicates a very good fit. & .040 & Cronbach's Alpha \\
\hline Factors & Average Variance Extracted (AVE) & Composite Reliability & 0.837 \\
System Quality (SQ) & 0.643 & 0.935 & 0.911 \\
Information Quality (IQ) & 0.598 & 0.839 & 0.892 \\
SeQ (SeQ) & 0.639 & 0.947 & 0.926 \\
Perceived Security (PS) & 0.688 & 0.945 & 0.891 \\
Perceived Privacy (PP) & 0.638 & 0.893 & 0.908 \\
Perceived Trust (PT) & 0.599 & 0.883 & 0.859 \\
Perceived Usefulness (PU) & 0.621 & 0.917 & 0.888 \\
Perceived Ease of Use (PE) & 0.608 & 0.901 & 0.866 \\
Perceived Risk (PR) & 0.672 & 0.923 & 0.882 \\
Users' Satisfaction (US) & 0.593 & 0.934 & 0.912 \\
E-Gov Usage (EU) & 0.612 & 0.895 & 0.961 \\
E-Gov Effectiveness (EE) & 0.657 & 0.935 & \\
\hline
\end{tabular}

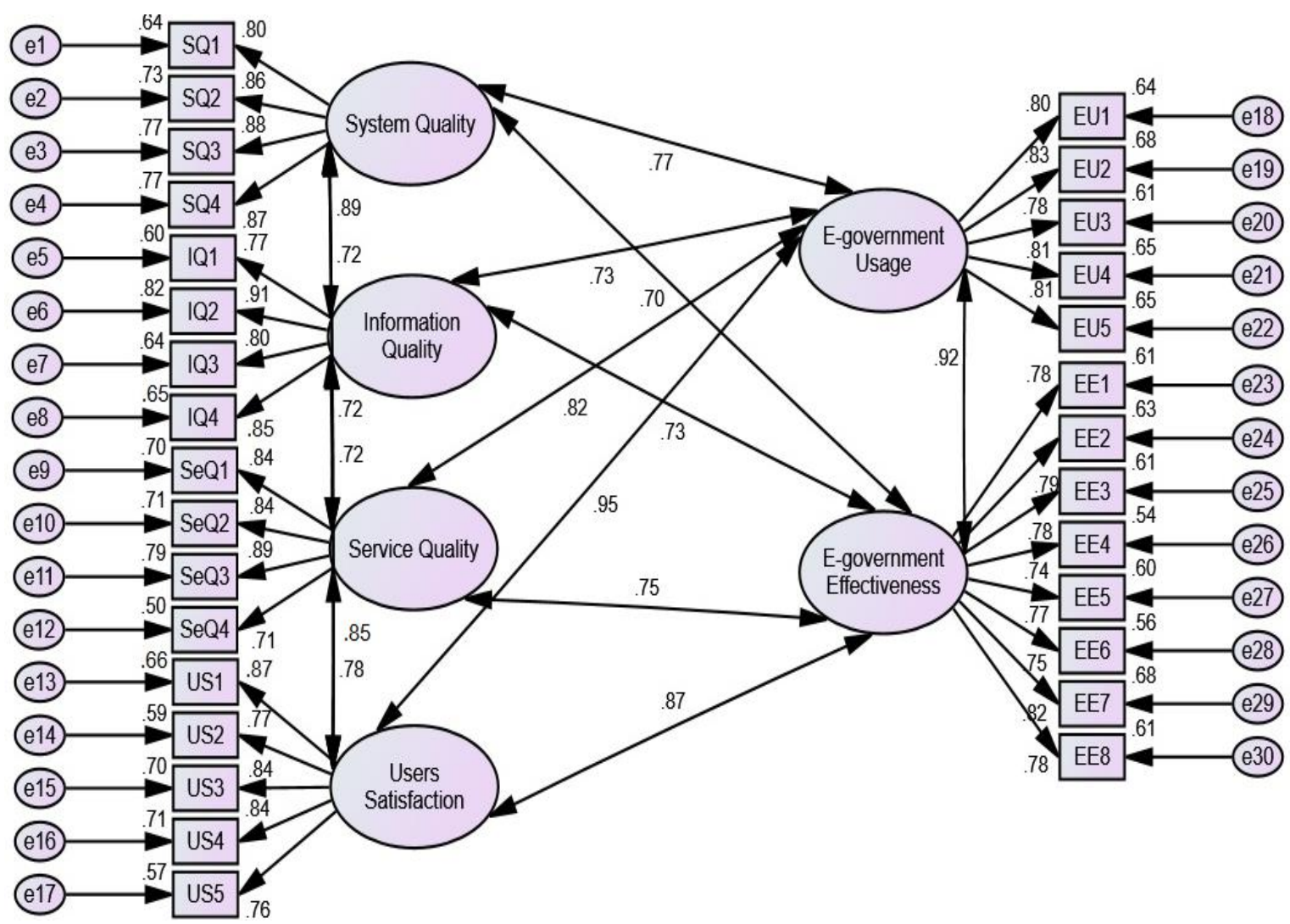

Figure 2. Measurement IS success model on E-Gov 


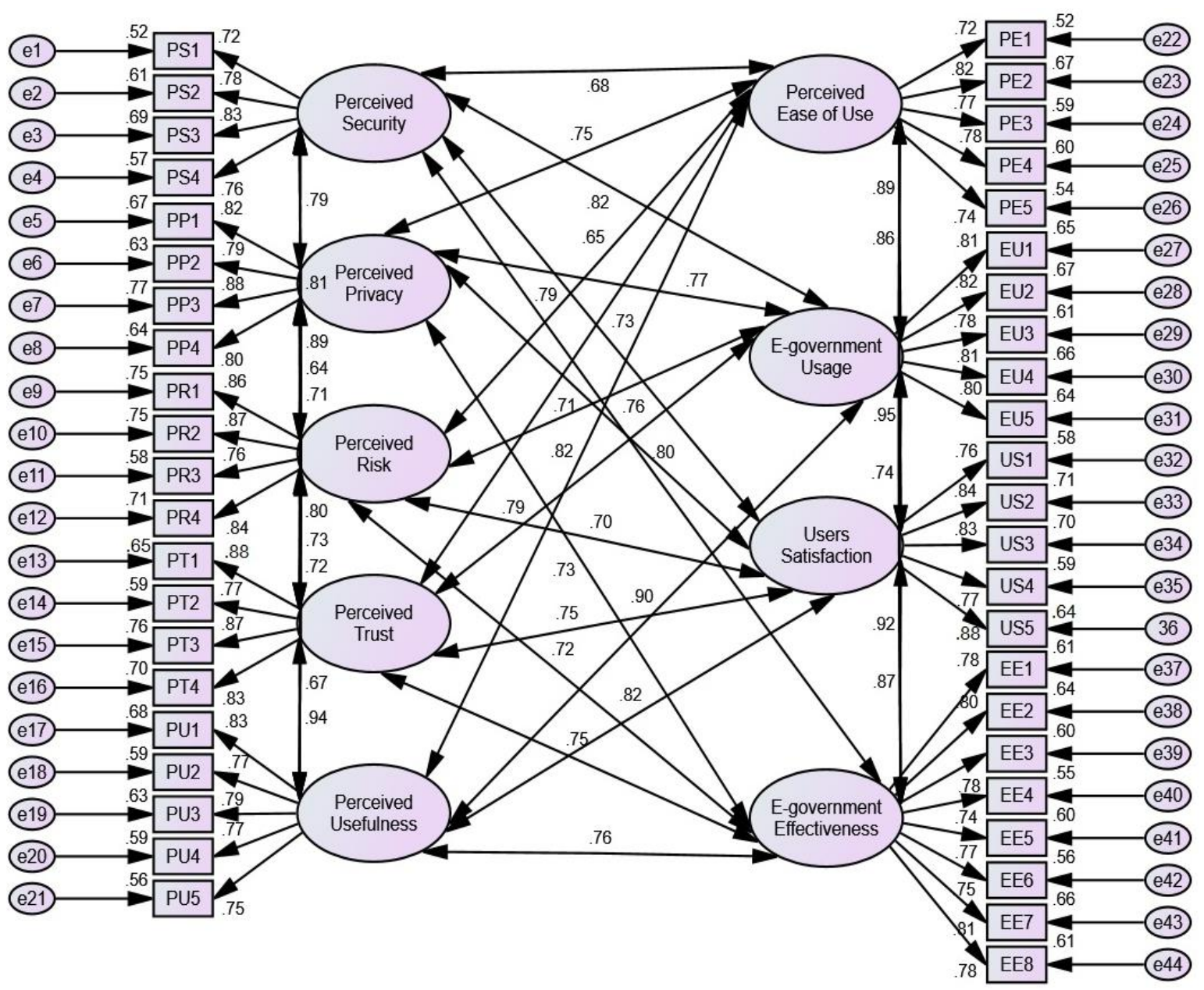

Figure 3. Measurement cybersecurity on E-Gov effectiveness

Table 2. Discriminant validity

\begin{tabular}{|c|c|c|c|c|c|c|c|c|c|c|c|c|}
\hline Variables & SQ & IQ & SeQ & PS & PP & PR & PT & $\overline{P U}$ & $\mathrm{PE}$ & UE & US & EE \\
\hline SQ & .809 & & & & & & & & & & & \\
\hline IQ & .490 & .882 & & & & & & & & & & \\
\hline SeQ & .332 & .403 & .897 & & & & & & & & & \\
\hline PS & .438 & .543 & .408 & .905 & & & & & & & & \\
\hline PP & .451 & .421 & .570 & .450 & .894 & & & & & & & \\
\hline PR & .345 & .439 & .572 & .530 & .507 & .917 & & & & & & \\
\hline PT & .378 & .432 & .438 & .469 & .472 & .395 & .837 & & & & & \\
\hline PU & .427 & .601 & .390 & .436 & .472 & .458 & .438 & .903 & & & & \\
\hline PE & .601 & .593 & .485 & .410 & .538 & .488 & .380 & .423 & .909 & & & \\
\hline UE & .409 & .429 & .378 & .395 & .419 & .436 & .437 & .438 & .540 & .889 & & \\
\hline US & .443 & .493 & .385 & .382 & .389 & .462 & .548 & .509 & .439 & .400 & .907 & \\
\hline EE & .349 & .498 & .405 & .495 & .472 & .431 & .341 & .511 & .491 & .381 & .457 & .912 \\
\hline
\end{tabular}

\subsection{Structural model}

In order to test the structural modelling, confirmatory factor analysis (CFA) was run as the second phase of the path analysis and structural equation modelling SEM, Table 3 illustrates the structural modelling of independent factors, and Table 4 demonstrates the structural modelling of mediator beside dependent factors. The data shown in these tables indicates the validity of this framework as well as its suitability to test the hypotheses of this study, see Figure 4 and Figure 5.

Figure 4 and Figure 5 represents the hypotheses between the twelve key constructs and the obtained results indicated that all fifteen hypotheses were accepted. Table 3 denotes values of the unstandardized coefficients along with the standard errors of the structural model that indicated major statistics of the model are significant, and thus demonstrating the model validity and the hypotheses testing results. 


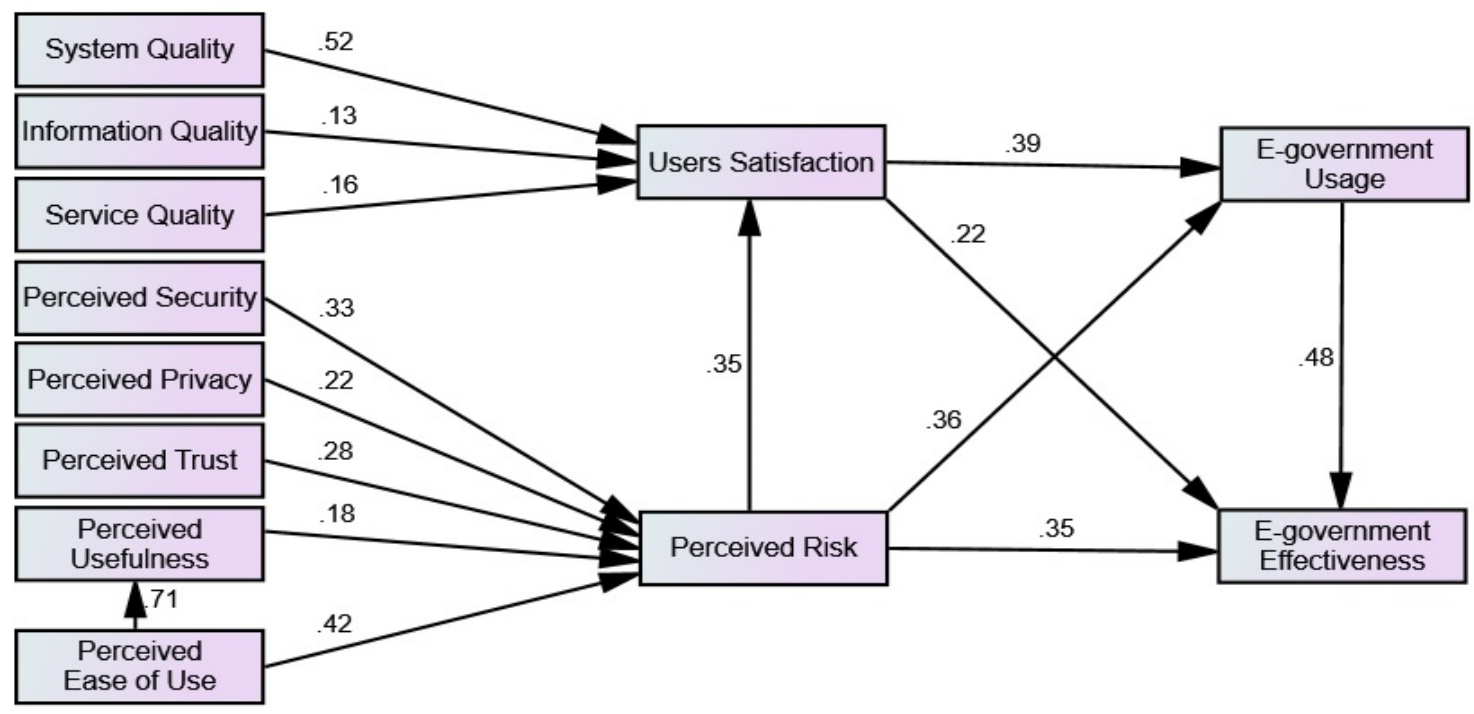

Figure 4. Research model hypothesis testing results

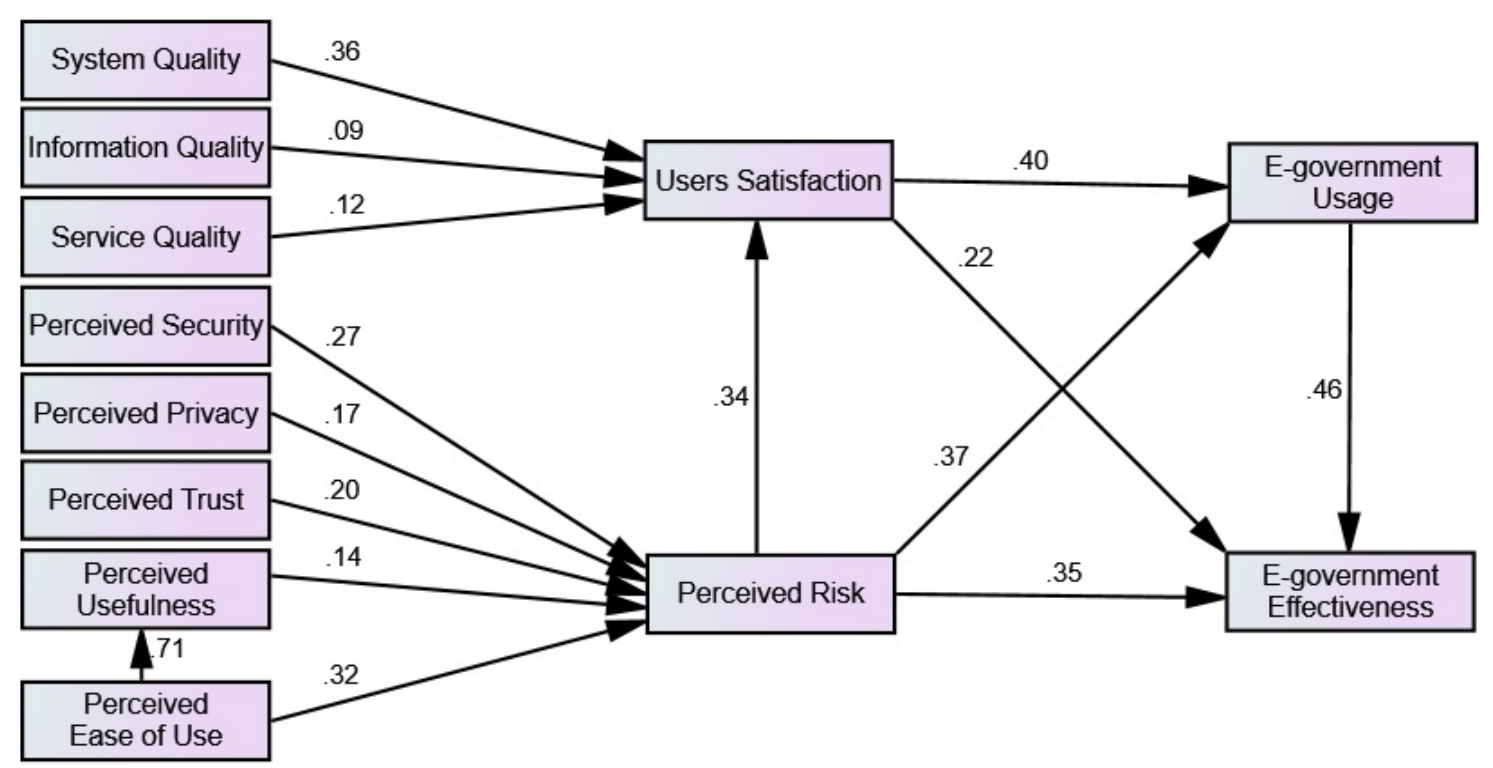

Figure 5. Research model hypothesis testing results

\subsubsection{Results of hypothesis testing}

All hypotheses are supported by these results illustrating the various relationships between the variables of the research model. Table 3 illustrates the unstandardized coefficients as well as the standard errors of the structural model by providing the required parameters. The Table 3 confirms that the SeQ, IQ, SQ, PS, PP, PR, PT, PU, PEU, EU, US, and E-Gov effectiveness.

As demonstrated in Table 3 and Figure 5, results display that there is a significant relationship among SQ and US $(\beta=.361, \mathrm{t}=6.087, \mathrm{p}<0.001)$, demonstrating that the hypothesis number one (H1) propose a positive and significant relationships, which means that is, this present sample showed that all respondents believe the SQ of E-Gov service it was a useful. The next direct effect is IQ and US ( $\beta=.086, t=1.835$, $\mathrm{p}<0.05)$, demonstrating that the hypothesis number two $(\mathrm{H} 2)$ recommend a positive and significant relations, which means that, this current sample show that all respondents believe the IQ of E-Gov service it was a useful. Added to the above result, the relationship between SeQ and US $(\beta=.118, t=2.253, p<0.05)$, representing that the hypothesis number three (H3) suggest a positive and significant relations, which means that this current sample show that all respondents believe the SeQ of E-Gov it was a useful. The following 
direct effect is PS and PR $(\beta=.266, t=3.380, p<0.001)$, demonstrating that the hypothesis number four $(\mathrm{H} 4)$ suggest a positive and significant relations, which means that is, in the present sample show that all respondents believe the PS of E-Gov service it was safety. Also, the relationship between PP and PR $(\beta=.170, t=2.119, \mathrm{p}<0.05)$, demonstrating that the hypothesis number five $(\mathrm{H} 5)$ suggest a positive and significant relations, which means that, in this current sample show that all respondents believe the PP of E-Gov service it was safety.

Table 3. Hypotheses testing results

\begin{tabular}{|c|c|c|c|c|c|c|c|c|}
\hline $\mathrm{H}$ & Independent & Relationship & Dependent & Estimate & $\begin{array}{l}\text { S.E } \\
\end{array}$ & C.R & $\mathrm{P}$ & Results \\
\hline H1 & SQ & & US & .361 & .059 & 6.087 & $* * *$ & Supported \\
\hline $\mathrm{H} 2$ & IQ & & US & .086 & .047 & 1.835 & $*$ & Supported \\
\hline H3 & $\mathrm{SeQ}$ & & US & .118 & .052 & 2.253 & $*$ & Supported \\
\hline $\mathrm{H} 4$ & PS & & PR & .266 & .079 & 3.380 & $* * *$ & Supported \\
\hline H5 & PP & & PR & .170 & .080 & 2.119 & $*$ & Supported \\
\hline H6 & PT & & PR & .205 & .072 & 2.854 & $* *$ & Supported \\
\hline $\mathrm{H} 7$ & PU & & PR & .137 & .079 & 1.733 & $*$ & Supported \\
\hline H8 & $\mathrm{PE}$ & & PR & .324 & .068 & 4.773 & $* * *$ & Supported \\
\hline H9 & $\mathrm{PE}$ & & PU & .712 & .049 & 14.578 & $* * *$ & Supported \\
\hline H10 & PR & & US & .344 & .061 & 5.636 & $* * *$ & Supported \\
\hline H11 & US & & EU & .403 & .063 & 6.376 & $* * *$ & Supported \\
\hline $\mathrm{H} 12$ & US & & $\mathrm{EE}$ & .219 & .043 & 5.065 & $* * *$ & Supported \\
\hline H13 & PR & & EU & .372 & .066 & 5.649 & $* * *$ & Supported \\
\hline $\mathrm{H} 14$ & PR & & EE & .346 & .044 & 7.833 & $* * *$ & Supported \\
\hline H15 & EU & & $\mathrm{EE}$ & .465 & .043 & 10.770 & $* * *$ & Supported \\
\hline
\end{tabular}

"Note: CR, critical ratio or t-value; ***p $<0.001 ; * * \mathrm{p}<0.01 ; * \mathrm{p}<0.05$ "

Similarly, the relationship between PT and PR $(\beta=.205, \mathrm{t}=2.854, \mathrm{p}<0.01)$, representing that the hypothesis number six (H6) suggest a positive and significant relations, In other words, in the current sample show that all respondents believe the PT of E-Gov service it was safety. Furthermore, the relationship between PU and PR $(\beta=.137, \mathrm{t}=1.733, \mathrm{p}<0.05)$, demonstrating that the hypothesis number seven $(\mathrm{H} 7)$ propose a positive and significant relations, In other words, in the current sample show that all respondents believe the PU of E-Gov service due it was a useful and safety. Also, the relationship between PEU and PR $(\beta=.324, \mathrm{t}=4.773, \mathrm{p}<0.001)$, representing that the hypothesis number eight (H8) suggest a positive and significant relations, which means that, in this current sample show that all respondents believe the PEU of E-Gov service due it was ease of use and safety. Furthermore, the relationship between PEU and PU $(\beta=.712, \mathrm{t}=14.578, \mathrm{p}<0.001)$, demonstrating that the hypothesis number nine (H9) suggest a positive and significant relations, which means that, in this current sample showed that all respondents believe the PEU of E-Gov service it was ease of use and useful.

Based to Table 3, the relationship between PR and US $(\beta=.344, \mathrm{t}=5.636, \mathrm{p}<0.001)$, demonstrating that the hypothesis number ten $(\mathrm{H} 10)$ propose a positive and significant relations, which means that is, this present sample showed that all respondents satisfied to use E-Gov service as it was useful and safety. Following hypothesis, the relationship between US and E-Gov services usage $(\beta=.403, t=6.376, p<0.001)$, demonstrating that the hypothesis number eleven (H11) propose a positive and significant relations, which means that the current sample show that all respondents satisfied to use E-Gov services due it was useful and safety. The following direct the relationship between US and EE $(\beta=.219, \mathrm{t}=5.065, \mathrm{p}<0.001)$, demonstrating that the hypothesis number twelve (H12) suggest a positive and significant relations, which means that, in the current sample show that all respondents satisfied to use E-Gov services due it was ease of use, useful and safety. Furthermore, the relationship between PR and E-Gov services usage $(\beta=.372, \mathrm{t}=5.649, \mathrm{p}<0.001)$, representing that the hypothesis number thirteen $(\mathrm{H} 13)$ propose a positive and significant relations, which means that, the current sample show that all respondents feeling safety to use E-Gov services due it was ease of use and useful.

Additionally to the above result, the relationship between PR and EE $(\beta=.346, \mathrm{t}=7.833, \mathrm{p}<0.001)$, representing that the hypothesis number fourteen $(\mathrm{H} 14)$ propose a positive and significant relations, which means that the current sample show that all respondents have a safety thus, they satisfied to use E-Gov service due it was ease of use and useful. The final direct effect is E-Gov services usage and E-Gov effectiveness $(\beta=.465, \mathrm{t}=10.770, \mathrm{p}<0.001)$, demonstrating that the hypothesis number fifteen (H15) propose a positive and significant relations, which means that this current sample show that all respondents use E-Gov services thus, they satisfied due it was ease of use, useful and safety. 


\subsubsection{Descriptive and analysis all factors}

The findings showed that majority of respondents agrees and strongly agrees that SQ of E-Gov services it was ease of use and useful. Thus, "this research defines SQ of E-Gov services as the degree where a user's believe that SQ of E-Gov services it was ease of use and useful". These finding are consistent with $[26,38]$, who argued that SQ of E-Gov services it was ease of use and useful. See Figure 6.

Also, the result shows that the majority of respondents agrees and strongly agrees that IQ of E-Gov services it was ease of use and useful. Thus, "this research defines IQ of E-Gov services as the degree where a user's believe that IQ of E-Gov services it was ease of use and useful". These finding are consistent with [41], who argued that IQ of E-Gov services it was ease of use and useful. See Figure 7.

Additionally, the findings showed that majority of respondents agrees and strongly agrees that $\mathrm{SeQ}$ of E-Gov services it was ease of use and useful. Thus, "this research defines SeQ of E-Gov services as the degree where a user's believe that SeQ of E-Gov services it was ease of use and useful". These finding are consistent with [26, 46], who argued that SeQ of E-Gov services it was ease of use and useful. See Figure 8.

Besides, the finding showed that majority of respondents agrees and strongly agrees that PS of E-Gov services it was safety. Thus, "this research defines PS of E-Gov services as the degree where a user's believe that PS of E-Gov services it was safety ". These finding are consistent with [48, 50], who argued that PT of E-Gov services it was ease of use and useful. See Figure 9.

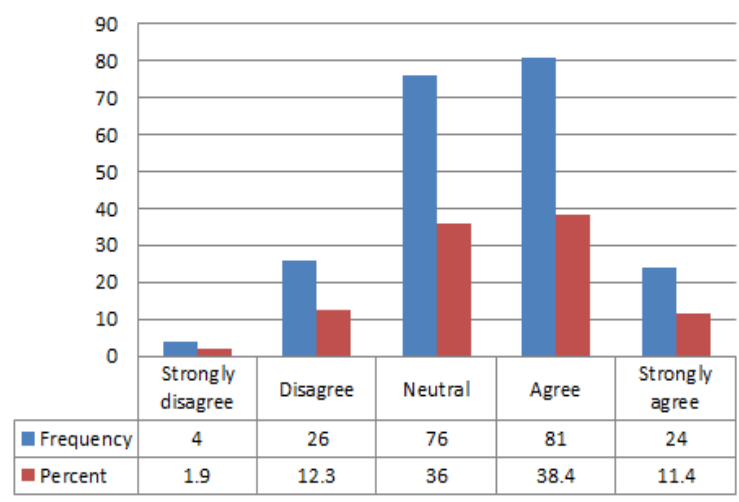

Figure 6. Measuring SQ of e-gov services

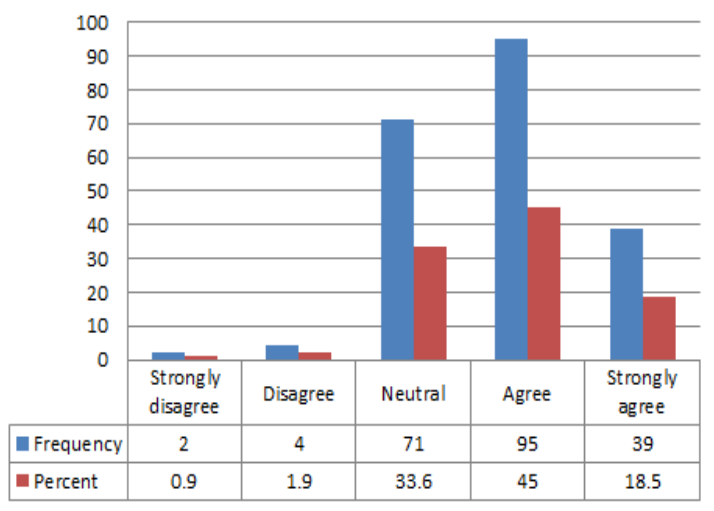

Figure 8. Measuring SeQ of e-gov services

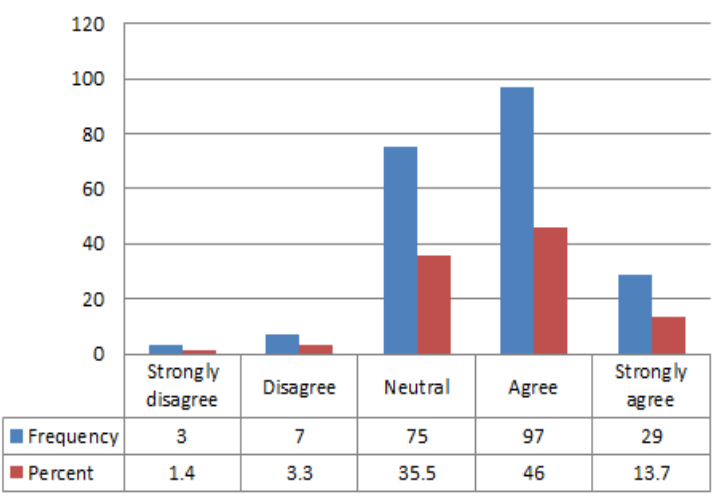

Figure 7. Measuring IQ of e-gov services

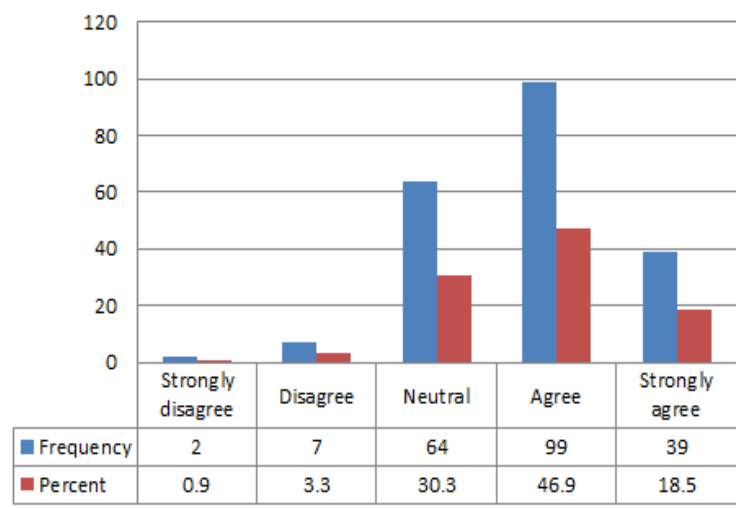

Figure 9. Measuring PS of e-gov services

Likewise, the findings showed that majority of respondents agrees and strongly agrees that PP of E-Gov services it was security and safety. Thus, "this research defines PP of E-Gov services as the degree where a user's believe that PP of E-Gov services it was security and safety ". These finding are consistent with [53-55], who argued that PT of E-Gov services it was ease of use and useful. See Figure 10.

Additionally, the findings showed that majority of respondents agrees and strongly agrees that PT of E-Gov services it was ease of use and useful. Thus, "this research defines PT of E-Gov services as the degree 
where a user's believe that PT of E-Gov services it was ease of use and useful". These finding are consistent with [16, 59], who argued that PT of E-Gov services it was ease of use and useful. See Figure 11.

Additionally, the findings showed that majority of respondent's agrees and strongly agrees that PU of E-Gov services it was ease of use and useful. Thus, "this research defines PU of E-Gov services as the degree where a user's believe that PU of E-Gov services it was ease of use and useful". These finding are reliable with [30, 67], who argued that PU of E-Gov services it was ease of use and useful. See Figure 12.

Additionally, the result demonstrates that most respondents agrees and strongly agrees that PEU of E-Gov services it was ease of use and useful. Thus, "this research defines PEU of E-Gov services as the degree where a user's believe that PEU of E-Gov services it was ease of use and useful". These finding are consistent with [69, 70], who argued that PEU of E-Gov services it was ease of use and useful. See Figure 13.

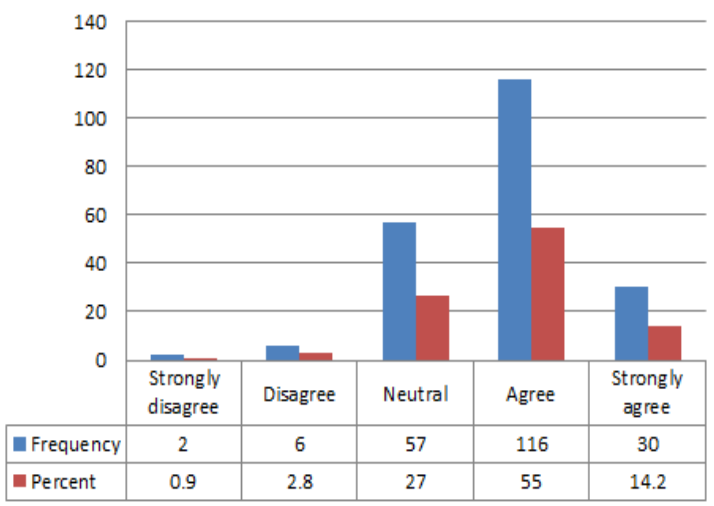

Figure 10. Measuring PP of e-gov services

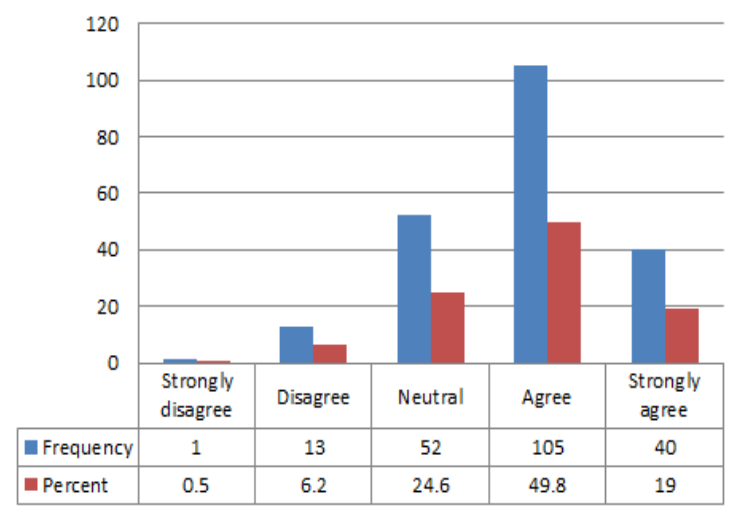

Figure 12. Measuring PU of e-gov services

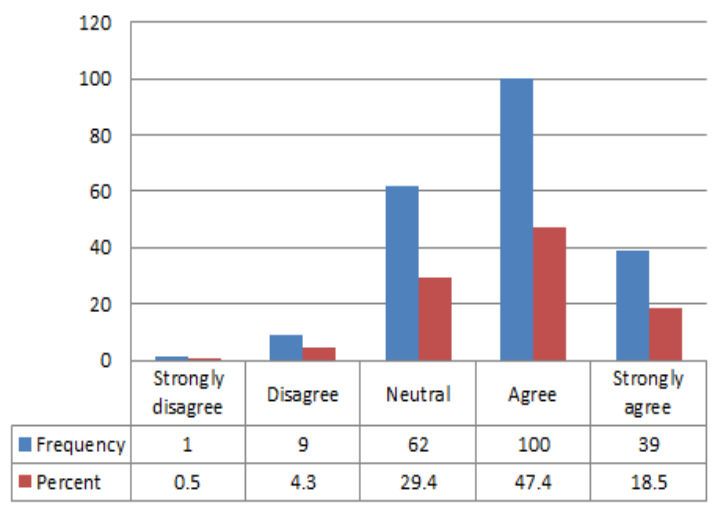

Figure 11. Measuring PT of e-gov services

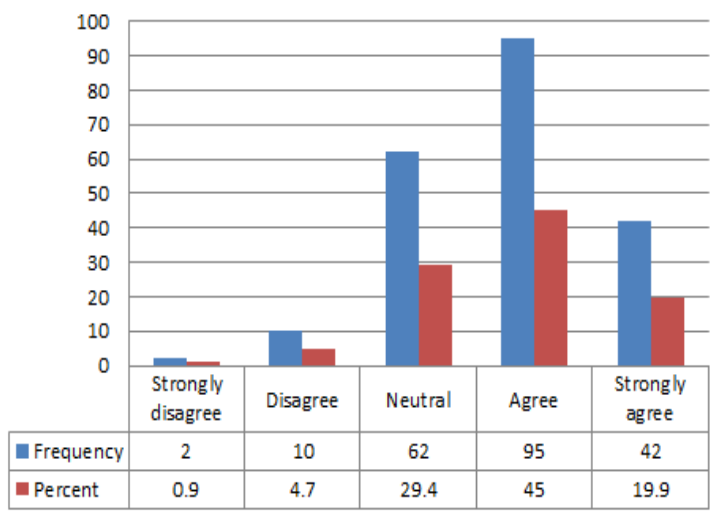

Figure 13. Measuring PEU of e-gov services

In addition, the result demonstrates that most respondents agree and strongly agrees that PR of E-Gov services it was ease of use, useful and safety. Thus, "this research defines PR of E-Gov services as the degree where a user's believe that PR of E-Gov services it was ease of use, useful and safety ". These finding are consistent with $[50,72,73]$, who argued that PEU of E-Gov services it was ease of use and useful. See Figure 14.

Also, the result demonstrates that most respondents agrees and strongly agrees, and they satisfied to use E-Gov services due it was ease of use, useful and safety. Thus, "this research defines users' satisfaction of E-Gov services as the degree where a user's believe and satisfied that E-Gov services it was ease of use, useful and safety ". These finding are consistent with [28, 36, 78], who argued that users' satisfaction of E-Gov services. See Figure 15.

Similarly, the result demonstrates that most respondents agrees and strongly agrees and they have a positive E-Gov services usage due it was ease of use, useful and safety. Thus, "this research defines E-Gov services usage as the degree where a user's believe that E-Gov services it was ease of use, useful and safety". 
These finding are consistent with [50,87, 88], who argued that E-Gov services usage it was ease of use and useful. See Figure 16.

Finally, the result demonstrates that most respondents agrees and strongly agrees, and they have a positive EE due it was ease of use, useful and safety. Thus, "this research defines EE as the degree where a user's believe that E-Gov services it was ease of use, useful and safety ". These finding are consistent with [9, 10, 90], who argued that attitude towards use E-Gov services it was ease of use and useful. See Figure 17.

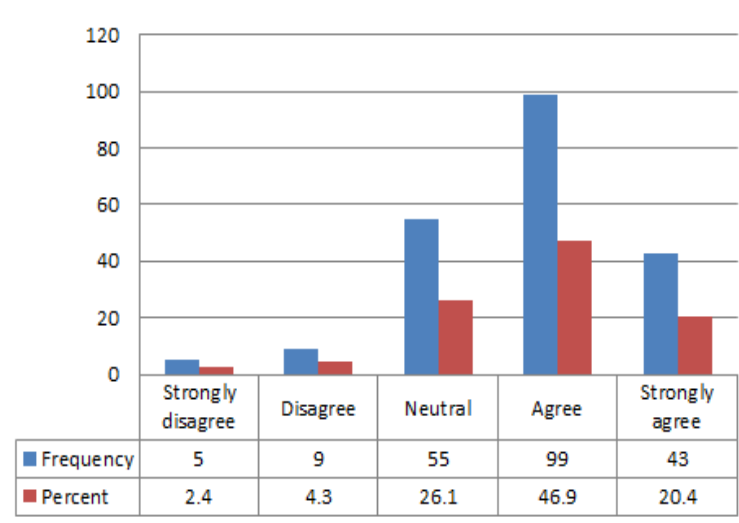

Figure 14. Measuring PR of e-gov services

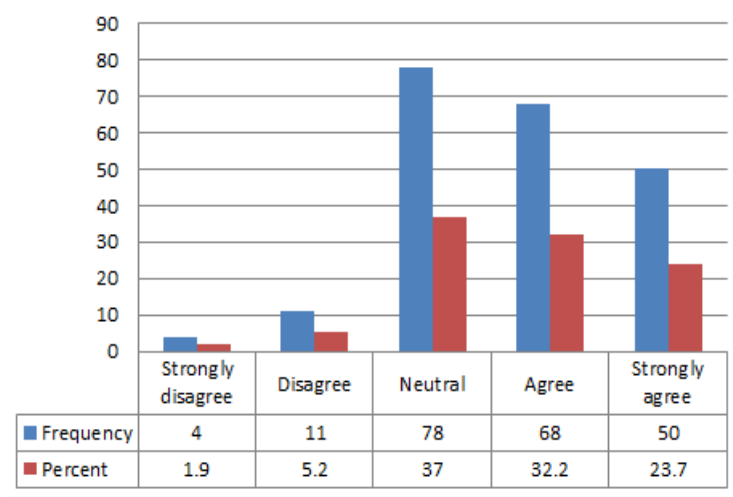

Figure 16. Measuring e-gov services usage

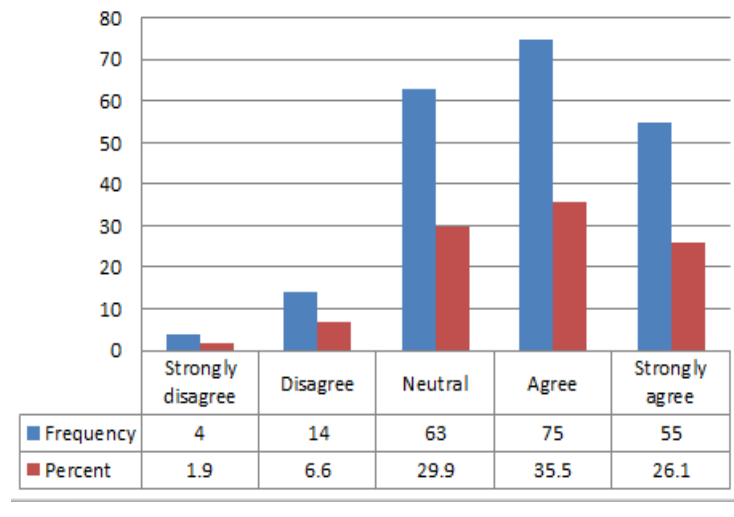

Figure 15. Measuring users' satisfaction of e-gov services

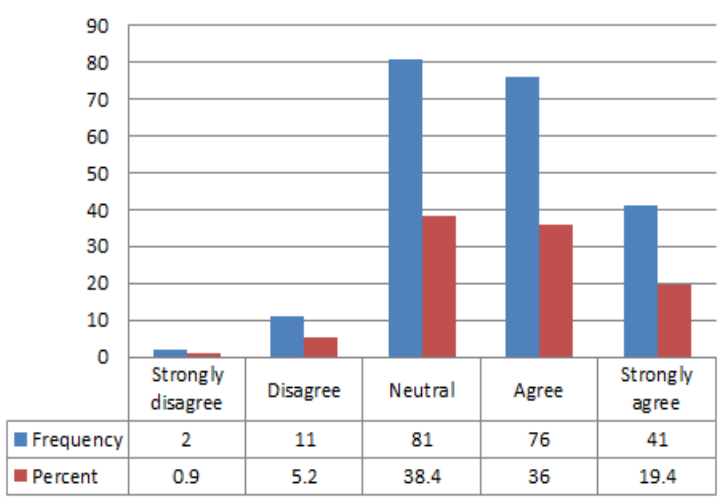

Figure 17. Measuring e-gov effectiveness

\section{DISCUSSION AND IMPLICATIONS}

Global Media Broadcast regarding privacy invasion and cybercrime raises people sensitivity, which hinders the E-Gov projects nationwide acceptance. Consequently, the E-Gov adoption initiatives differ based on citizens' commitment to accept. Nevertheless, the anticipated possibility of E-Gov services is not utilized in several nations globally. Additionally, citizens nowadays have being more apprehensive regarding online transaction's risks and, moreover, gradually more aware regarding their security, trust, as well as privacy. Consequently, this present study aimed to design a new model on (IS) success model, and cybersecurity factors, which in turn, affect E-Gov service usage and its efficiency in KSA. Based on the model proposed, the relationships among fifteen of the hypotheses discovered that the effectiveness of E-Gov service usage within the following factors: SeQ, IQ, SQ, PS, PR, PT, PP, PU, EU, US, PEU, and EE. See Figure 1.

This current research showed that of E-Gov systems users in KSA has a great perception of users' satisfaction that could cause greater evaluations for the SQ, information, and service. The results of this research suggest that the core constructs of (IS) success model have solid impacts on users' satisfaction of E-Gov service usage in KSA. Our empirical results show that SeQ, IQ, SQ, positively influence on the users' satisfaction of E-Gov service. In the meantime, users' satisfaction was positively influence on the E-Gov 
service usage and effectiveness. Consistent with prior (IS) success model literature, the core constructs of the (SeQ, IQ, SQ, and users' satisfaction of E-Gov service) have a strong and significant impact on Saudi E-Gov service. These results are reliable with many earlier researches like; [39, 52, 64, 66], who claimed that there is a positive relationship between (IS) success model on E-Gov service use and users' satisfaction. Additionally, the results of this research indicate that the core constructs of TAM and cybersecurity factors have persuasive impacts on PR of E-Gov service usage in KSA. Our empirical results demonstrate that PS, PP, PT, PU, PEU positively influence on the PR of E-Gov service usage. In the meantime, PR was positively influence on the E-Gov service usage and effectiveness. Consistent with prior cybersecurity factors and TAM literature, the core constructs of the (PS, PP, PT, PU, PEU, PR) have a significant and strong influence on Saudi E-Gov service. These findings are coherent with earlier researches such as [50, 52, 75-77], who agree that there is a positive relationship between PR of E-Gov service and TAM with cybersecurity factors on E-Gov service use.

In addition, citizens in KSA operating E-Gov system put forth a huge effort to achieve positive results. Thus, this research results demonstrate that the core constructs of the (IS) success model, TAM, and cybersecurity factors have strong impacts on PR and users' satisfaction on E-Gov service, which affect the usage of E-Gov service and usefulness. These results can be compared with studies results of acceptance model, since the E-Gov acceptance investigation is based on TAM modelling. These results demonstrated, PEU, PU and PS as positive influence factors with E-Gov services acceptance. The results relate other studies results $[52,85]$. The SQ factor was also identified as significant predictor of E-Gov services usage by users according with [25] findings. Additionally, amount of IQ factor and SeQ on E-Gov services was identified as significant corresponding to [32] findings. Moreover, PT factor in E-Gov was also identified as significant according to PR results of $[50,52]$. Therefore, that developed model combines multiple studies factors to reflect the reality of E-Gov acceptance in a better way, specifically with PR and users' satisfaction. The results showed a significant and positive outcome on E-Gov service acceptance, even with having few negative perceptions of security and risk issues of E-Gov use, and the privacy, individuals who considered themselves more capable of using E-Gov systems categorized as average users whereas, more motivated and willingly to utilize the system.

The study findings are consistent along with the empirical findings of [100]. A reasonable justification for these findings is that as users become more familiar and competent with using E-Gov systems, thus, they exclude themselves as targeted to cybersecurity threats. According to the finding of this research has three theoretical implications; the first implication, (IS) success model (SeQ, IQ, SQ) have strong influences on users' satisfaction of E-Gov service usage in KSA. The second implication, cybersecurity model (PS, PT, PP,) have solid impacts on PR of E-Gov service usage in KSA. The third implication, TAM model (PEU, PU) have strong influences on PR of E-Gov service usage in KSA, all theoretical implications was positively affecting the E-Gov service usage and effectiveness. Moreover, this research findings are reliable to previous discussion results, whereas it could be shown that (IS) success model, cybersecurity model, and TAM model including its practices and propositions, is reliable with the E-Gov service usage, this conclusion is mentioned by many experts in this area of study $[31,50,55,75,76,79,80,90,91]$. Further the mentioned theoretical implications, this research results further propose practical implications for policy makers and practitioners. Thus, as of a practical perspective, the results underline the security, trust, and privacy importance of handling risk perceived of E-Gov effectiveness and E-Gov service. Consequently, efforts of increasing E-Gov adoption in KSA must certify various securities, risk, privacy, and trust constructs as mentioned in this study. Privacy and security mechanisms must be convincing to citizens in place. Reflecting the maturity of security, privacy, risk, and trust in E-Gov service context, the cybersecurity building mechanisms of well known, trusted online and Web 2.0 applications must be analysed for adaptability; correspondingly, the maturity of SeQ, IQ, SQ must be considered in the context of E-Gov.

\section{CONCLUSION AND FUTURE WORK}

This study results support the E-Gov service usage, which affect E-Gov service effectiveness and usage in KSA. Additionally, Findings presented that SeQ, IQ, SQ positively impact users' satisfaction of E-Gov service, and PS, PU, PT, PP, PEU positively impact the PR of E-Gov service usage, both which affect the E-Gov services usage and effectiveness. Consequently, the results of this study demonstrate all hypotheses were acceptable. Accordingly, all hypotheses results were significant and positive, which clarify that, most of the KSA citizens are using the E-Gov services; therefore, future work must consider the creation of citizens regulations on E-Gov services use in various purposes. Also, this research has numerous limitations that future investigation can focus on. The investigation of E-Gov systems (IS) success models is comparatively new to KSA. Therefore, the results in this discussion of E-Gov categories or user groups 
cannot be generalized, however, it is considered to be a decent basis for additional investigations. Furthermore, this study sample size was an additional limitation. Finally, a cross cultural validation using a large sample in another place requires a greater generalization of the model developed on other countries.

\section{ACKNOWLEDGEMENT}

The author extends his appreciation to the Deanship of Scientific Research at King Faisal University for supporting this work.

\section{REFERENCES}

[1] D. R. Compeau and C. A. Higgins, "Computer self-efficacy: Development of a measure and initial test," MIS quarterly, vol. 1, no. 2, pp. 189-211, 1995.

[2] P. T. Jaeger, "The endless wire: E-government as global phenomenon," Government information quarterly, vol. 20, no. 4, pp. 323-331, 2003.

[3] V. P. Aggelidis and P. D. Chatzoglou, "Using a modified technology acceptance model in hospitals," International journal of medical informatics, vol. 78, no. 2, pp. 115-126, 2009.

[4] L. A. Muñoz, et al., "Analysing the scientific evolution of e-Government using a science mapping approach," Government Information Quarterly, vol. 34, no. 3, pp. 545-555, 2017.

[5] A. Zuiderwijk, et al., "Acceptance and use predictors of open data technologies: Drawing upon the unified theory of acceptance and use of technology," Government information quarterly, vol. 32, no. 4, pp. 429-440, 2015.

[6] S. Kim, et al., "An institutional analysis of an e-government system for anti-corruption: The case of OPEN," Government Information Quarterly, vol. 26, no. 1, pp. 42-50, 2009.

[7] M. T. Dishaw and D. M. Strong, "Extending the technology acceptance model with task-technology fit constructs," Information \& management, vol. 36, no. 1, pp. 9-21, 1999.

[8] K. J. Bwalya, "Factors affecting adoption of e-government in Zambia," The Electronic Journal of Information Systems in Developing Countries, vol. 38, no. 1, pp. 1-13, 2009.

[9] K. Layne and J. Lee, "Developing fully functional E-government: A four stage model," Government information quarterly, vol. 18, no. 2, pp. 122-136, 2001.

[10] P. T. Jaeger and K. M. Thompson, "E-government around the world: Lessons, challenges, and future directions," Government Information Quarterly, vol. 20, no. 4, pp. 389-394, 2003.

[11] A. M. Eidaroos, et al., "Heuristic evaluation for e-Government websites in Saudi Arabia," in A. Aloqbi, (eds.), SIC: The Third Saudi International Conference, Conference Proceedings, 2009.

[12] K. Zafiropoulos, et al., "Assessing the adoption of e-government services by teachers in Greece," Future Internet, vol. 4 , no. 2 , pp. 528-544, 2012.

[13] W. Munyoka and M. Maharaj, "Understanding eGovernment utilisation within the SADC," in 2017 IST-Africa Week Conference (IST-Africa), pp. 1-10, 2017.

[14] H. N. Siddiqui, "Investigation of intention to use e-commerce in the Arab countries: A comparison of self-efficacy, usefulness, culture, gender, and socioeconomic status in Saudi Arabia and the United Arab Emirates," Ph.D. thesis, Graduate School of Computer and Information Sciences Nova Southeastern University, 2008.

[15] Y. S. Wang and Y. W. Liao, "Assessing eGovernment systems success: A validation of the DeLone and McLean model of information systems success," Government information quarterly, vol. 25, no. 4, pp. 717-733, 2008.

[16] F. Bannister and R. Connolly, "Trust and transformational government: A proposed framework for research," Government Information Quarterly, vol. 28, no. 2, pp. 137-147, 2011.

[17] United Nations E-Government Survey, 2016. [Online] Available: http://workspace.unpan.org/sites/Internet/Documents/UNPAN97453.pdf.

[18] S. S. Al-Gahtani, et al., "Information technology (IT) in Saudi Arabia: Culture and the acceptance and use of IT," Information \& management, vol. 44, no. 8, pp. 681-691, 2007.

[19] M. Hamner and F. Al-Qahtani, "Enhancing the case for Electronic Government in developing nations: A people-centric study focused in Saudi Arabia," Government Information Quarterly, vol. 26, no. 1, pp. 137-143, 2009.

[20] M. O. Al-Fakhri, et al., "E-government in Saudi Arabia: Between promise and reality," International Journal of Electronic Government Research (IJEGR), vol. 4, no. 2, pp. 59-85, 2008

[21] M. Alshehri and S. Drew, "Challenges of e-government services adoption in Saudi Arabia from an e-ready citizen perspective," World Academy of Science, Engineering and Technology, vol. 66, pp. 1053-1059, 2010.

[22] M. Alassim, et al., "Understanding Factors Influencing E-Government Implementation in Saudi Arabia from an Organizational Perspective," International Journal of Information and Communication Engineering, vol. 11, no. 7, pp. 894-899, 2017.

[23] H. Armbruster, et al., "Organizational innovation: The challenge of measuring non-technical innovation in largescale surveys," Technovation, vol. 28, pp. 644-657, 2008.

[24] J. R. Evans and W. M. Lindsay, "The management and control of quality," South-western collage pub, vol. 5, pp. 115-128, 2011.

[25] J. Lee, et al., "The willingness of e-Government service adoption by business users: The role of offline service quality and trust in technology," Government Information Quarterly, vol. 28, no. 2, pp. 222-230, 2011.

Int J Elec \& Comp Eng, Vol. 10, No. 5, October 2020 : 4937 - 4955 
[26] W. H. Delone and E. R. McLean, "The DeLone and McLean model of information systems success: a ten-year update," Journal of management information systems, vol. 19, no. 4, pp. 9-30, 2003.

[27] M. H. Hsu and C. M. Chiu, "Internet self-efficacy and electronic service acceptance," Decision Support Systems, vol. 38, no. 3, pp. 369-381, 2004.

[28] W. H. Delone and E. R. McLean, "Information system success: The quest for dependent variable," Information Systems Research, vol. 3, no. 1, pp. 60-95, 1992.

[29] Y. S. Wang, "The adoption of electronic tax filing systems: an empirical study," Government Information Quarterly, vol. 20, no. 4, pp. 333-352, 2003.

[30] F. Davis, et al., "User acceptance of computer technology: a comparison of two theoretical models," Management Science, vol. 35, no. 8, pp. 982-1003, 1989.

[31] M. A. Shareef, et al., "e-Government Adoption Model (GAM): differing service maturity levels," Government Information Quarterly, vol. 28, no. 1, pp. 17-35, 2011.

[32] M. Rehman, et al., "Factors influencing e-Government adoption in Pakistan," Transforming Government: People, Process and Policy, vol. 6, no. 3, pp. 258-282, 2012.

[33] National Institute of Standards and Technology (NIST), "Framework for improving critical infrastructure cybersecurity version 1.1," NIST Cybersecurity Framework, 2018. https://doi.org/10.6028/NIST.CSWP.04162018.

[34] V. Venkatesh, et al., "Consumer acceptance and use of information technology: Extending the unified theory of acceptance and use of technology," MIS Quarterly, vol. 36, no. 1, pp. 157-178, 2012.

[35] A. Bracha and D. J. Brown, "Affective decision making: A theory of optimism bias," Games and Economic Behavior, vol. 75, no. 1, pp. 67-80, 2012.

[36] P. B. Seddon, "A respecification and extension of the DeLone and McLean model of IS success," Information systems research, vol. 8, no. 3, pp. 240-253, 1997.

[37] T. S. H. Teo, et al., "Trust and electronic government success: An empirical study," Journal of management information systems, vol. 25, no. 3, pp. 99-132, 2008.

[38] S. Wangpipatwong, et al., "Quality enhancing the continued use of e-government web sites: Evidence from e-citizens of Thailand," International Journal of Electronic Government Research (IJEGR), vol. 5, no. 1, pp. 19-35, 2009.

[39] X. Papadomichelaki and G. Mentzas, "e-GovQual: A multiple-item scale for assessing e-government service quality," Government information quarterly, vol. 29, no. 1, pp. 98-109, 2012.

[40] L. Carter and F. Belanger, "The Utilization of e-Government Services: Citizen Trust, Innovation and Acceptance Factors," Information System Journal, vol. 15, no. 1, pp. 5-25, 2005.

[41] V. R. McKinney, et al., "The measurement of web-customer satisfaction: An expectation and disconfirmation approach," Information systems research, vol. 13, no. 3, pp. 296-315, 2002.

[42] A. Maes and G. Poels, "Evaluating quality of conceptual modelling scripts based on user perceptions," Data \& Knowledge Engineering, vol. 63, no. 3, pp. 701-724, 2007.

[43] O. Glassey and O. F. Glassey, "A proximity indicator for e-government: The smallest number of clicks," Journal of e-Government, vol. 1, no. 4, pp. 5-20, 2005.

[44] K. Omar, et al., "eGovernment service quality assessed through the public value lens," in International Conference on Electronic Government, pp. 431-440, 2011.

[45] L. F. Pitt, et al., "Service quality: a measure of information systems effectiveness," MIS quarterly, vol. 19, no. 2, pp. 173-187, 1995.

[46] J. Moad, “Asking users to judge IS,” Datamation, vol. 35, no. 21, pp. 93-100, 1989.

[47] A. Jansen and S. Ølnes, "The nature of public e-services and their quality dimensions," Government Information Quarterly, vol. 33, no. 4, pp. 647-657, 2016.

[48] V. Tountopoulos, et al., "Supporting security and trust in complex e-government services," in Secure and Trustworthy Service Composition, pp. 219-233, 2014.

[49] C. Mazumdar, et al., "On information security issues in e-governance: Developing country views," CSDMS Journal, 2009.

[50] F. Bélanger and L. Carter, "Trust and risk in e-Government adoption," Journal of Strategic Information Systems, vol. 17, no. 2, pp. 165-176, 2008.

[51] D. Gilbert, et al., "Barriers and benefits in the adoption of e-Government," International Journal of Public Sector Management, vol. 17, no. 4, pp. 286-301, 2004.

[52] M. Horst, et al., "Perceived usefulness, personal experiences, risk perception and trust as determinants of adoption of e-government services in The Netherlands," Computers in Human Behavior, vol. 23, no. 4, pp. 1838-1852, 2007.

[53] S. Virkar, "Breaking Barriers to e-Government: Overcoming Obstacles to Improving European Public Services," European Commission, Brussels, 2007.

[54] S. Prentice and G. Dewnarain, "The Future of the Internet: Fundamental Trends, Scenarios and Implications to Heed," Gartner, 2012. Available: http://www.gartner.com/technology/core/products/research/topics/emergingTrendsTechnologies.jsp.

[55] T. J. Perez, "Municipal E-Government Security: What is the greatest challenge?" in 2015 48th Hawaii International Conference on System Sciences, pp. 2263-2271, 2015.

[56] L. van Zoonen, "Privacy concerns in smart cities," Government Information Quarterly, vol. 33, no. 3, pp. 472-480, 2016.

[57] M. I. Manda and J. Backhouse, "Addressing trust, security and privacy concerns in e-government integration, interoperability and information sharing through policy: a case of South Africa," in International Conference on Information Resources (CONF-IRM), p. 67, 2016. 
[58] V. Moen, et al., "Vulnerabilities in e-governments," International Journal of Electronic Security and Digital Forensics, vol. 1, no. 1, pp. 89-100, 2007.

[59] S. Samiee and P. G. Walters, "Relationship marketing in an international context: a literature review," International business review, vol. 12, no. 2, pp. 193-214, 2003.

[60] S. A. B. M. Yusof and M. H. Abdulraheem, "Real Factors which Impact on Decision Making in the Egovernment," in 2015 6th International Conference on Intelligent Systems, Modelling and Simulation, pp. 252-255, 2015.

[61] M. Warkentin, et al., "Encouraging citizen adoption of e-government by building trust," Electronic markets, vol. 12, no. 3, pp. 157-162, 2002.

[62] L. Dombrowski, et al., "E-government intermediaries and the challenges of access and trust," ACM Transactions on Computer-Human Interaction (TOCHI), vol. 21, no. 2, pp. 1-22, 2014.

[63] C. J. Tolbert and K. Mossberger, "The effects of e-government on trust and confidence in government," Public administration review, vol. 66, no. 3, pp. 354-369, 2006.

[64] M. Kurfal1, et al., "Adoption of e-government services in Turkey," Computers in Human Behavior, vol. 66, pp. 168-178, 2017.

[65] F. F. Reichheld and P. Schefter, "E-loyalty: Your secret weapon on the web," Harvard Business Review, vol. 78, no. 4, pp. 105-113, 2000.

[66] E. W. Welch, et al., "Linking citizen satisfaction with e-government and trust in government," Journal of Public Administration Research and Theory, vol. 15, no. 3, pp. 371-391, 2004.

[67] V. Venkatesh and F. D. Davis, "Theoretical extension of the technology acceptance model: four longitudinal field studies," Management Science, vol. 46, no. 2, pp. 186-204, 2000.

[68] P. A. Pavlou, "Consumer acceptance of electronic commerce. Integrating trust and risk with the technology acceptance model," International Journal of Electronic Commerce, vol. 7, no. 3, pp. 101-134, 2003.

[69] S. Y. Hung, et al., "User acceptance of intergovernmental services: an example of electronic document management system," Government Information Quarterly, vol. 26, no. 2, pp. 387-397, 2009.

[70] S. Y. Hung, et al., "User acceptance of mobile e-government services: an empirical study," Government Information Quarterly, vol. 30, no. 1, pp. 33-44, 2013.

[71] A. Nechaev and O. Antipina, "Analysis of the Impact of Taxation of Business Entities on the Innovative Development of the Country," European Research Studies Journal, vol. 19, no. 1, pp. 71-83, 2016.

[72] E. A. Rosa, "Metatheoretical foundations for post-normal risk," Journal of risk research, vol. 1, no. 1, pp. 15-44, 1998.

[73] J. Lee and H. R. Rao, "Task complexity and different decision criteria for online service acceptance: A comparison of two e-government compliance service domains," Decision Support Systems, vol. 47, no. 4, pp. 424-435, 2009.

[74] G. Cairns, et al., "Reputation, relationships, risk communication, and the role of trust in the prevention and control of communicable disease: A review," Journal of Health Communication, vol. 18, no. 12, pp. 1550-1565, 2013.

[75] I. Almarashdeh and M. K. Alsmadi, "How to make them use it? Citizens acceptance of M-government," Applied Computing and Informatics, vol. 13, no. 2, pp. 194-199, 2017.

[76] A. Al Khattab, et al. "The effect of trust and risk perception on citizen's intention to adopt and use E-Government services in Jordan," Journal of service science and management, vol. 8, no. 3, pp. 279-290, 2015.

[77] L. C. Schaupp and L. Carter, "The impact of trust, risk and optimism bias on E-file adoption," Information Systems Frontiers, vol. 12, no. 3, pp. 299-309, 2010.

[78] D. Gefen, "TAM or just plain habit: a look at experienced online shoppers," Journal of End User Computing, vol. 15 , no. 3, pp. 1-13, 2003.

[79] Y. K. Dwivedi, et al., "Moving towards maturity: challenges to successful e-government implementation and diffusion," The DATABASE for Advances in Information Systems, vol. 42, no. 4, pp. 11-22, 2012.

[80] J. Floropoulos, et al., "Measuring the success of the Greek taxation information system," International Journal of Information Management, vol. 30, no. 1, pp. 47-56, 2010.

[81] N. P. Rana, et al., "Evaluating the validity of IS success models for the electronic government research: An empirical test and integrated model," International Journal of Electronic Government Research, vol. 9, no. 3, pp. 1-22, 2013.

[82] N. P. Rana, et al., "Theories and theoretical models for examining the adoption of egovernment services," $e$-Service Journal, vol. 8, no. 2, pp. 26-56, 2012.

[83] C. W. Chen, "Impact of quality antecedents on taxpayer satisfaction with online tax-filing systems - an empirical study," Information \& Management, vol. 47, no. 5, pp. 308-315, 2010.

[84] R. Gotoh, "Critical factors increasing user satisfaction with egovernment services," Electronic Government, an International Journal, vol. 6, no. 3, pp. 252-264, 2009.

[85] S. E. Colesca and L. Dobrica, "Adoption and Use of E-Government Services: The Case of Romania," Journal of Applied Research and Technology, vol. 6, no. 3, pp. 204-217, 2008.

[86] Y. Liu and C. Zhou, "A citizen trust model for e-government," in Proceedings of IEEE International Conference on Software Engineering and Service Sciences, pp. 751-754, 2010.

[87] X. Jiang, "Enhancing Users' Continuance Intention to E-Government Portals: An Empirical Study," in 2011 International Conference on Management and Service Science, pp. 1-4, 2011.

[88] A. Bhattacherjee, et al., "Information technology continuance: A theoretic extension and empirical test," Journal of Computer Information Systems, vol. 49, no. 1, pp. 17-26, 2008. 
[89] Y. Wang and T. Tang, "Assessing customer perceptions of website service quality in digital marketing environments," Journal of Organizational and End User Computing, vol. 15, no. 3, pp. 14-31, 2003.

[90] R. Santa, et al., "Technological innovation and operational effectiveness: Their role in achieving performance improvements," Production Planning \& Control: The Management of Operations, vol. 25, no. 12, pp. 969-979, 2014.

[91] S. Shan, et al., "Research on e-government evaluation model based on the principal component analysis," Information Technology and Management, vol. 12, no. 2, pp. 173-185, 2011.

[92] A. Savoldelli, et al., "Understanding the e-government paradox: Learning from literature and practice on barriers to adoption," Government Information Quarterly, vol. 31, pp. S63-S71, 2014.

[93] R. V. Krejcie and D. W. Morgan, "Determining sample size for research activities," Educational and psychological measurement, vol. 30, no. 3, pp. 607-610, 1970.

[94] J. F. Hair, et al., "An assessment of the use of partial least squares structural equation modeling in marketing research," Journal of the academy of marketing science, vol. 40, no. 3, pp. 414-433, 2012.

[95] R. Nabafu and G. Maiga, "A Model of Success Factors for Implementing Local e Government in Uganda," Electronic Journal of e-Government, vol. 10, no. 1, pp. 31-46, 2012.

[96] S. J. Barnes and R. Vidgen, "Interactive e-government: evaluating the web site of the UK Inland Revenue," Journal of Electronic Commerce in Organizations (JECO), vol. 2, no. 1, pp. 42-63, 2004.

[97] J. Benamati, et al., "Clarifying the integration of trust and TAM in e-commerce environments: implications for systems design and management," IEEE Transactions on Engineering Management, vol. 57, no. 3, pp. 380-393, 2010.

[98] A. Bhattacherjee, "An empirical analysis of the antecedents of electronic commerce service continuance," Decision Support Systems, vol. 32, no. 2, pp. 201-214, 2001.

[99] C. Fornell and D. F. Larcker, "Evaluating structural equation models with unobservable variables and measurement error," Journal of marketing research, vol. 18, no. 1, pp. 39-50, 1981.

[100] J. P. Carlin, "Detect, disrupt, deter: A whole-of-government approach to national security cyber threats," Harvard National Security Journal, vol. 7, pp. 391-436, 2016. 